\title{
Collaborative group work and increased diversity through Wikipedia editing
}

\author{
Laurel Stvan*
}

\begin{abstract}
This paper details how a collaborative assignment to edit Wikipedia entries on linguistic topics can help students practice and improve their research skills and navigate group work through an engaged learning task. It describes strategies for group formation, types of cognitive skills that were deployed in the task, equitable distribution of workload and ways that individual student contributions to the project were tracked and assessed, along with project feedback from student reflections. The editing task is also shown as a way to increase gender diversity and widen the language background of the site's editors.
\end{abstract}

Keywords. pedagogy; group work; gender diversity; Wikipedia

1. Introduction. New types of classroom research projects and discipline-specific service-learning projects (Villeneuve 2019; Rotramel et al. 2019) have been emerging through the help of the Wiki Education Foundation (WikiEdu)'s efforts to bring skills in editing Wikipedia articles into the university. In my most recent rounds of using their training and assignments to teach linguistics, I found benefits in harnessing these page-editing tasks to shape meaningful undergraduate assignments. In the class, students worked on individual content exercises where they gathered data and applied theories. But an additional learning goal was for students to show they could find, assess, and contribute definitions and claims supported with relevant references, to build up a shared linguistics article. Using Wikipedia editing in the classroom contributes multiple pedagogical benefits. These include highlighting open access and science communication to promote outreach to the larger community; convincing academe of the validity of Wikipedia to practicing scholarly research; learning about Wikipedia's own plagiarism and copyright rules; discussing content gaps within the discipline of Linguistics; using the remote learning opportunities that the editing dashboard provides for both individual learning and group projects; and improving the diversity of Wikipedia editors. This paper emphasizes the latter two: a demonstration of particular benefits of research-related group work, and the benefits of article editing in bringing a more gender-diverse set of editors to the task of improving Wikipedia pages.

2. Pedagogical context. Since 2015 the LSA has offered Wikipedia Editathon sessions to help members learn skills that they can apply to create or improve Wikipedia pages on languages, linguistic concepts, and notable linguists. At the LSA annual meetings, representatives from WikiEdu have also encouraged faculty to try editing assignments in their classes. Meeting sessions featuring digital tools have also highlighted Wikipedia's role in generating student interest in linguistics (McCulloch 2017). I am an LSA member who acquired Wikipedia editing skills through these opportunities. I was eager to tap student interests to build a more balanced online coverage of the discipline and to provide my students the chance to gain experience in sharing their new linguistic knowledge with others.

\footnotetext{
* Thanks to Helaine Blumenthal at WikiEdu.org for inviting me to participate in a focus group during WikiConference North America in 2018 in Columbus Ohio, where instructors who had been implementing Wikipedia assignments in our classrooms could compare notes. And to UT Arlington's Office of the Provost for sponsoring me in the 2021 ACUE Course in Effective Online Teaching Practices. And also to the anonymous reviewers of this paper for helpful structuring suggestions. Author: Laurel Stvan, University of Texas at Arlington (stvan@uta.edu).
}

(C) 2021 Author(s). Published by the LSA with permission of the author(s) under a CC BY license. 
The linguistics courses I teach have been traditionally face-to-face sessions. The last time I used this assignment, however, the COVID-19 pandemic interrupted our semester, so the group editing assignment took part during the emergency switch to online teaching. Since the students' drafting and editing of Wikipedia pages is done through an online interface, this project did not require much re-adjustment for remote work.

Wikipedia provides a familiar starting place for students to begin engaging with the class content in a more experiential way. They have read Wikipedia, but are usually not aware of the ways it gets created--and what gets left out. Learning to assess a gap and craft the information and citations to expand a page fits my pedagogical goal of providing active learning (Meyers \& Jones 1993), where, rather than having students only listen to lectures, projects engage their interest in a topic through activities allowing them to clarify, question, consolidate, while working together to create new knowledge.

3. The group assignment. Unless the class is an advanced seminar, students will be learning linguistic background content together at the same time that they are learning Wiki editing skills. This occurred with my Spring 2020 undergraduates, an advanced core class for linguistics majors, with 38 students. While students may not be ready to create new summaries of class topics at the start, they can still build up pieces that improve a page. Their project goal is to work with a group of classmates to research, expand the content, and build up background sources for an existing Wikipedia page on a linguistics topic.

Though students traditionally report disliking required group work (Carpenter 2006, Voyles et al. 2015), fearing penalties due to uneven participant effort, students doing group editing have found it to be more enjoyable than they expected. I found that these groups work best when I provide pre-selected topics, creating a list of linguistics-related pages that need building up. Instructors can find a list of page stubs by topic within Wikipedia (Category 2020). I provided more possible topics than the desired number of groups, to offer a real choice. Students looked up the existing pages, then signed up for a page, self-selecting into a group based on a topic they wanted to research. I set a minimum number of participants for each group. Some people signed up with a friend, but many students met new people in the class through this shared interest, which, as with techniques suggested by Nilson \& Goodson (2018), helped to counter isolation and enhance a sense of community when we moved online.

Once topics were selected, I set up groups in Canvas, our university's LMS. Some groups preferred to use GroupMe or FaceTime to meet on their own schedule, which also works fine. Because we did not pivot to online until spring break, students had seen each other in person already. But even without initial face-to-face conversations, they can use an electronic method for their small group meetings. Eventually they will have a joint sandbox within the class Wikipedia site in which to draft notes. But students may still prefer to use an audio or video channel while they work. Breakout rooms were added to Teams since that semester, so I plan to use those spaces in the future. That way I can be on call for the initial group meetings as students work on particular aspects of editing.

4. Group tasks. To start their research, I asked group members to work in a shared online document to examine their page's content and structure.

4.1. CONTENT. For gathering materials to expand their page, I gave a list of suggestions. Here I illustrate three. The first asked them to consider: "What kinds of examples would illustrate what your topic covers. Where could you find them? Don't limit yourself to English examples!" 
The second suggestion noted: "If you read another language, you can translate prose and sources from a page in another language's version of this topic on Wikipedia." My last class, for example, included multiple students minoring in three languages, so they used these portals:

- Spanish version: https://es.wikipedia.org/wiki/Wikipedia:Portada

- Korean version: https://ko.wikipedia.org/wiki/

- German version: https://de.wikipedia.org/wiki/Wikipedia:Hauptseite

The third suggestion said: "You will have to work together to gather a list of scholarly sources to read. (i.e., Check Google Scholar for the titles, then track them down in the university library databases. Don't buy any articles!)" This point shows how Wikipedia editing builds on the same library skills and ways to evaluate sources that students would normally deploy in writing individual research papers.

4.2. STRUCTURE. In shaping a linguistic resource, after reviewing WikiEdu's training in page development, in their joint draft they considered these aspects:

- As you learn about and work on defining the topic, consider how your page's topic is similar to, or different from, another related topic. Note down other pages that might be good models for this one.

- Identify what things are missing from the current article. This should be an ongoing list.

- Create a list of section headings to add as you expand the page.

- Note what claims need citations. Are there any false or unclear claims right now?

- Plan out who will summarize each section and add each cited source for your group.

- Consider what other existing pages should link to this one. And, what words on this page could link out to other Wikipedia pages.

The goal of brainstorming is for them to deploy choosing, evaluating, and creating, thus incorporating the increasing cognitive levels spelled out in Anderson and Krathwohl (2001)'s re-framing of Bloom's taxonomy. As the group's lists of tasks evolved, students were graded on steps along the way to improving their shared page.

5. How group work was assessed. While each group worked jointly on one Wikipedia page, several steps they took in learning how to use the editing interface were individually assessed, generally as completion-point exercises through the WikiEdu dashboard, e.g., set up an account, do the training on Wikipedia policies, add a citation to an existing article (they could find claims with missing citations with Citation Hunt), and respond to your group's peer reviews by classmates.

But they all needed to contribute to the joint draft in the sandbox page. And to contribute edits again once their material was moved to the live page. In a normal semester, the groups also gave an end of term presentation showing what they had worked on. In the pandemic semester I changed this to individual written reflections on the process of improving the page.

Methods for tracking what students individually contributed are built into Wikipedia itself. For example, Figure 1 shows a screenshot of the edit history of a page that students were working on. Here we can see that on May 9, three different users edited the page. The number of characters that each added or deleted is visible; if they left notes, a summary of the change is also shown. Such changes can be viewed by anyone for any Wikipedia page. In this case, since I knew the students behind each username, I could track who actually worked on each page, and when. 


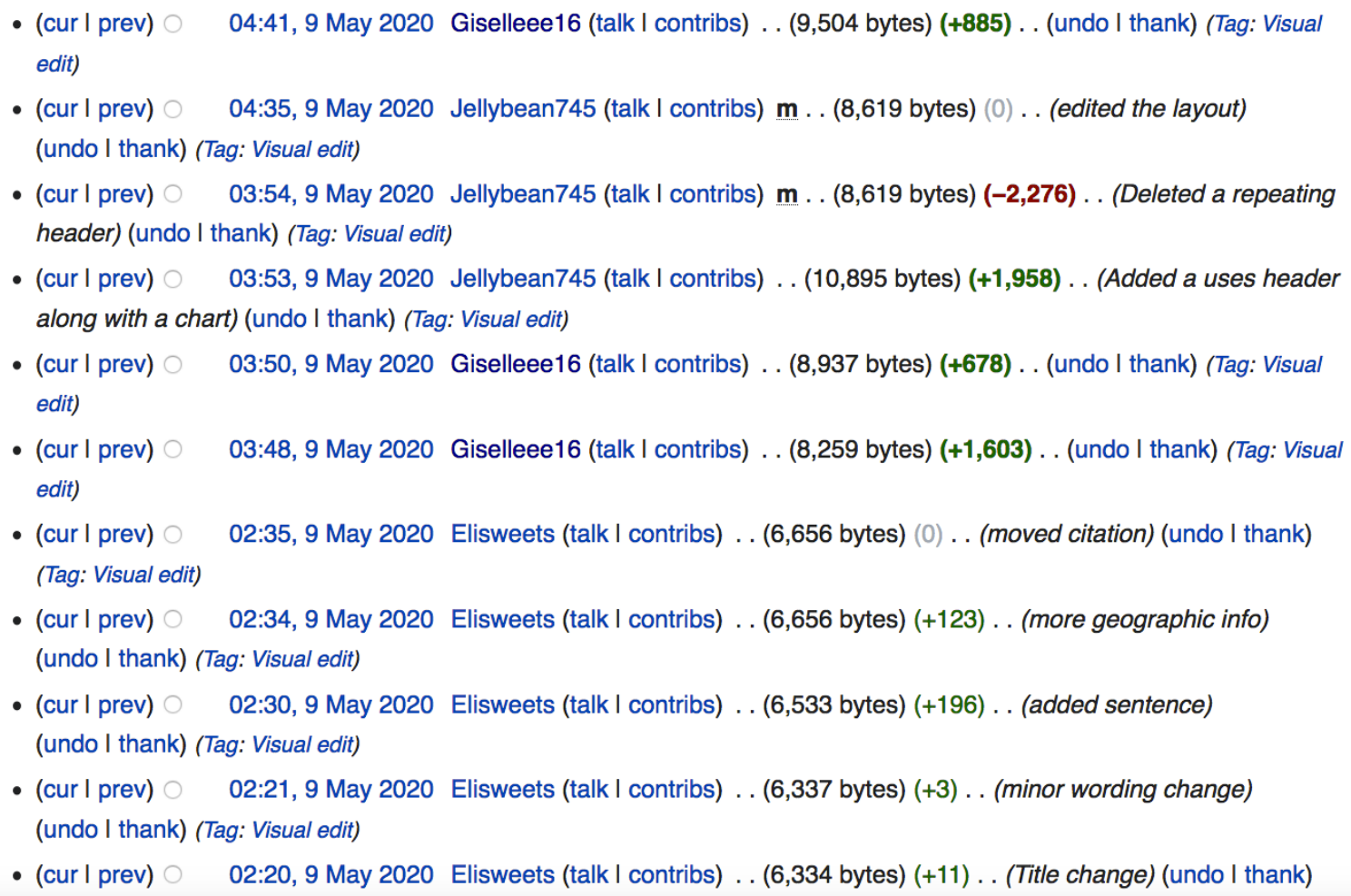

Figure 1. A section of the edit history of one group's chosen page.

5.1. A BEFORE PAGE. It is also possible to see the changes in an actual live page between any two dates. This is an aspect that students can share with the class for a before-and-after wind-up group presentation, or can examine at any point to check the page's progress.

Figure 2, for example, shows the stub of a page that one group started with, on the Fis Phenomenon.

Fis phenomenon is a phenomenon of child language acquisition that demonstrates that perception of phonemes occurs earlier than the ability of the child to produce those phonemes. It is also illustrative of a larger theme in child language acquisition: that skills in linguistic comprehension generally precede corresponding skills in linguistic production.

The name comes from an incident reported in 1960 by J. Berko and R. Brown. ${ }^{[1]} \mathrm{A}$ child referred to his inflatable plastic fish as a fis. However, when adults asked him, "Is this your fis?" he rejected the statement. When he was asked, "Is this your fish?" he responded, "Yes, my fis." This shows that although the child could not produce the phoneme $/ J /$, he could perceive it as being different from the phoneme $/ \mathrm{s} /$. In some cases, the sounds produced by the child are actually acoustically different, but not significantly enough for others to distinguish ${ }^{[2]}$ since the language in question does not make such contrasts.

\section{References}

1. ^ J. Berko and R. Brown (1960). "Psycholinguistic Research Methods". In P. Mussen (ed.). Handbook of Research methods in Child Development. New York: John Wiley. pp. 517-557.

2. ^ Fromkin, V. (Ed.) (2000). Linguistics: An Introduction to Linguistic Theory. Malden, MA: Blackwell Publishing. ISBN 0-631-19711-7. Chapter 7: Phonology.

['st $\Lambda$ b] This linguistics article is a stub. You can help Wikipedia by expanding it.

Figure 2. The initial page before students edited it. 
I pulled up what the page looked like in April of 2018, the last time anyone had previously edited the page. The screenshot in Figure 2 shows the whole page at that point, which was just two paragraphs and two references. This left many openings for students to develop the topic further.

5.2. AN AFTER PAGE. In contrast, Figures 3 and 4 show parts of the page after the student group finished with it in May of 2020. Figure 3 shows what is now just the lead to the article, but in addition, students have added new sections, which automatically generated a table of contents for the rest of the article. Their four new sections cover perception vs production of sounds in language acquisition, experimental studies related to the phenomenon, and so on.

Fis phenomenon is a phenomenon during a child's language acquisition that demonstrates that perception of phonemes occurs earlier than a child's ability to produce the phoneme. It is also illustrative of a larger theme in child language acquisition: that skills in linguistic comprehension generally precede corresponding skills in linguistic production. The name comes from an incident reported in 1960 by J. Berko and R. Brown, in which a child referred to his inflatable plastic fish as a fis. However, when adults asked him, "Is this your fis?" he rejected the statement. When he was asked, "Is this your fish?" he responded, "Yes, my fis." This shows that although the child could not produce the phoneme $/ \mathrm{J} /$, he could perceive it as being different from the phoneme /s/. In some cases, the sounds produced by the child are actually acoustically different, but not significantly enough for others to distinguish since the language in question does not make such contrasts.

\begin{tabular}{|l|}
\hline Contents [hide] \\
1 Occurrences in ASL \\
2 Language acquisition \\
2.1 Perception \\
2.2 Production \\
3 Experiments and studies \\
3.1 Covert contrast as a stage in the acquisition of phonetics and phonology \\
3.2 Invariant order of phonological development \\
3.3 Juliette Blevins and claims \\
4 See also \\
5 References
\end{tabular}

Figure 3. The page structure after students edited it.

In addition, Figure 4 shows that students have found and incorporated a total of 11 scholarly sources to the page as footnotes that back up the claims they developed. By studying other pages, learning about Wikipedia's criteria for unbiased resources, gathering and summarizing library materials, and building on each other's contributions, students were able to apply their growing linguistic knowledge to create a better online resource. 


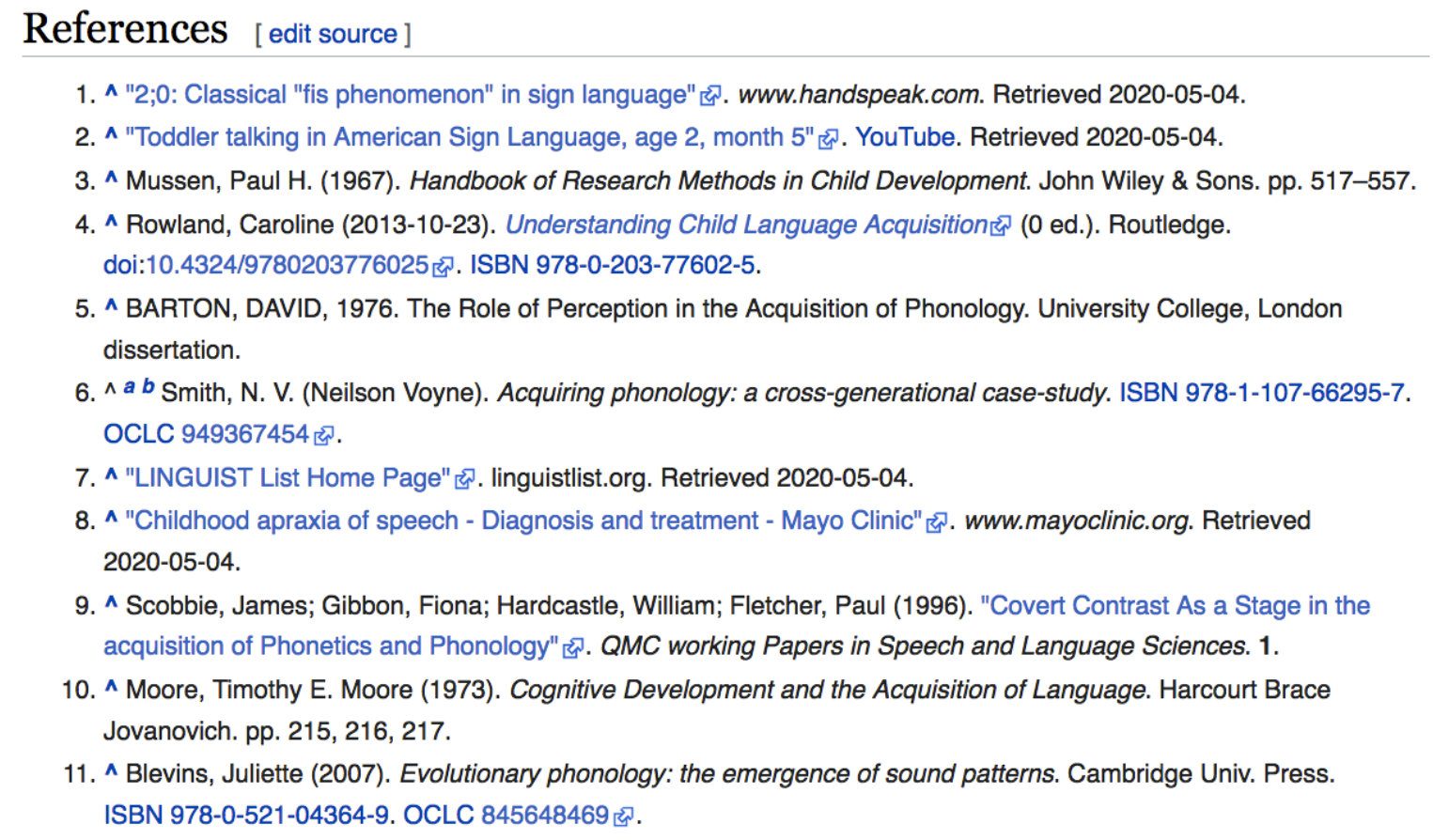

Figure 4. References added by students.

6. Student feedback. Among the topics discussed in their final reflection papers, some students mentioned group work aspects of the project. Three student's comments illustrate parts that class members found to be beneficial: a) They liked the peer review they received from other groups and from each other about what they planned to change on their page: "Especially in working with such a short article to start with, the feedback from group members and being able to collaborate in this way definitely made the experience less pressured." ${ }^{1} \mathrm{~b}$ ) They liked that their work was open to the wider world of readers and editors, even after the class was over: "We'll continue to get feedback on our edits to this page from other users beyond just our classmates and the page will hopefully continue to grow." And c) they liked that they could pool and build on the sources the group found, so that no one had to shoulder the burden of all the research steps: "I doubt I would have nearly as much information to work with had we not been pooling our sources and discussing possible citations and references." In short, as Nilson and Goodson (2018: 55) note, for group assignments "students have to need each other to come to defensible conclusions or develop and assess alternative solutions."

7. Incorporating diversity. One well-documented demographic divide in creating Wikipedia content relates to gender, e.g., Wagner et al. (2016) on which editors create main page edits; Cabrera et al. (2018) on which editors contribute to talk pages; and Balch (2019), noting that no more than $20 \%$ of Wikipedia editors are female. Linguistics classes, however, enroll a majority of female students. The makeup of linguistics programs can be seen in the information gathered annually by the Linguistic Society of America from departments across the U.S. Figure 5 shows

\footnotetext{
${ }^{1}$ Student names are withheld to maintain student privacy.
} 
an excerpt from their report (LSA Annual Report 2020:25), showing the average student enrollment in linguistics programs by gender.

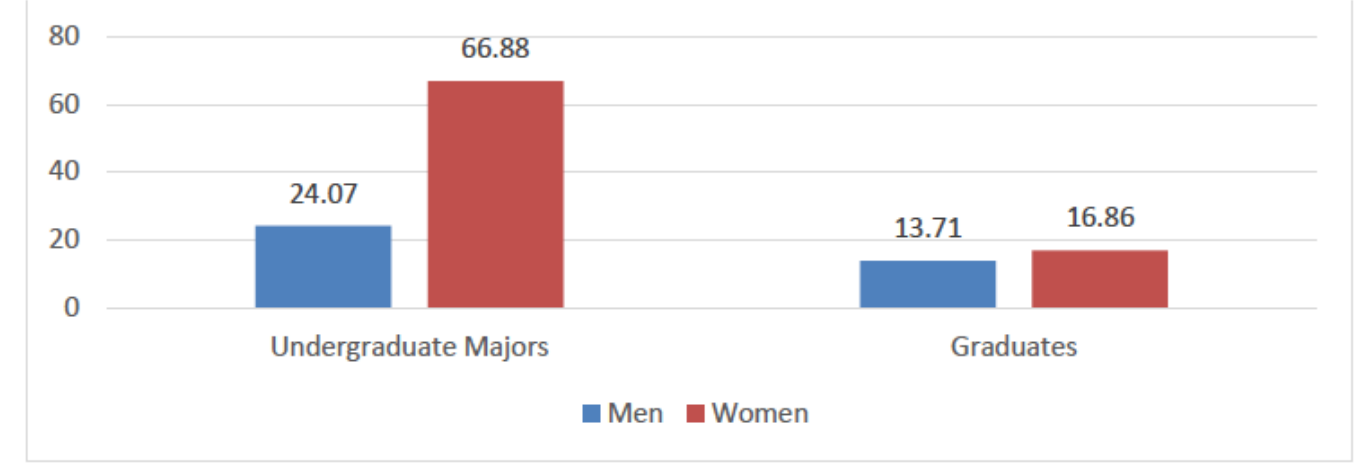

Figure 5. Average number of linguistics students enrolled from 2013 to 2019, by gender.

And indeed, the five classes in which I used student Wikipedia editing contained a total of 83 students. Of these, 63 identified as female and 20 as male. Since Wikipedia editors are still mainly male, while students in linguistics are mainly female, tasks bringing a familiarity with Wikipedia editing skills to this student body provide a way to increase the number of female editors shaping the content of this online resource. In helping students to recognize gender bias, the activity makes relevant one aspect of justice, equity, diversity and inclusion (JEDI) affecting classroom materials. Furthermore, in the class we talk about gaps in Wikipedia's language coverage, and how increasing the range of editors can also address this. Our university is an urban R1, a Hispanic-serving institution ranked as having the fifth most diverse undergraduates in the nation. As a white, female, tenured professor, I point to this setting to highlight the untapped potential of student diversity, aiming to empower the class to draw on their own collective language backgrounds and understanding of the world to improve Wikipedia entries.

8. Tools and conclusions. I end with information for instructors planning to use group Wikipedia editing assignments in their own classroom. Besides the links in the references to linguistics pages on Wikipedia categorized as stubs in need of improvement, the Citation Hunt tool, and articles on the pedagogical value of Wikipedia editing assignments in other disciplines, below are two introductory pages from the Wiki Education organization:

- https://wikiedu.org/ Introduces the free support for instructors

- https://ashboard.wikiedu.org/ Illustrates some of the page analytics

In conclusion, working on discipline-specific Wikipedia pages helped students appreciate the vetting and research required to create a source they likely already used. Students achieved the learning outcomes of practicing how to find, use, and cite academic material to expand an online article. In researching their topics, students found the assignment of editing a page together allowed a fairer evaluation of how each person's contribution counted, found it reassuring to compare notes on the shape and depth of the page, and found it a practical way to locate appropriate academic resources. Finally, involving linguistics students, in particular, helps balance out the skewed ratio of Wikipedia editors, who are still mainly male and English speaking. 


\section{References}

Anderson, Lorin W. \& David R. Krathwohl. 2001. A taxonomy for learning, teaching, and assessing: A revision of Bloom's taxonomy of educational objectives. New York: Addison Wesley Longman.

Balch, Oliver. 2019. Making the edit: Why we need more women in Wikipedia. The Guardian [Web page]. https://www.theguardian.com/careers/2019/nov/28/making-the-edit-why-weneed-more-women-in-wikipedia.

Cabrera, Benjamin, Björn Ross, Marielle Dado \& Maritta Heisel. 2018. The gender gap in Wikipedia talk pages. Proceedings of the Twelfth International AAAI Conference on Web and Social Media (ICWSM-2018): 572-575. https://aaai.org/ocs/index.php/ICWSM/ICWSM18/paper/view/17829.

Carpenter, Jason M. 2006. Effective teaching methods for large classes. Journal of Family \& Consumer Sciences Education 24(2). 13-23. https://www.natefacs.org/Pages/v24no2/v24no2Carpenter.pdf.

Category: Linguistics stubs. https://en.wikipedia.org/wiki/Category:Linguistics_stubs. (29 February 2020.)

Citation Hunt. https://citationhunt.toolforge.org/en?id=56cccfla (28 February 2021.)

The Linguistic Society of America. 2020. The State of Linguistics in Higher Education Annual Report 2019, 7th edn. Issued March 2020. https://www.linguisticsociety.org/sites/default/files/Annual_Rept_Final_2019.pdf.

McCulloch, Gretchen. 2017. Stumbling across linguistics online: Tumblr and Wikipedia. Datablitz: Getting high school students into linguistics: Current activities and future directions. Linguistic Society of America, Austin, TX. 7 January 2017. https://docs.google.com/ presentation/d/1dIhSqG4zOdyzEjOUYOjT24WS_ThCVty88AlQM5ix6IA/ edit\#slide=id.g1a60eb1 6f0_0_786. (23 June 2019.)

Meyers, Chet \& Thomas B. Jones. 1993. Promoting active learning: Strategies for the college classroom. San Francisco: Jossey-Bass.

Nilson, Linda B. \& Ludwika A. Goodson. 2018. Online teaching at its best: Merging instructional design with teaching and learning research. San Francisco: Jossey-Bass.

Rotramel, Ariella, Rebecca Parmer \& Rose Oliveria. 2019. Engaging women's history through collaborative archival Wikipedia projects. Journal of Interactive Technology and Pedagogy 14. https://jitp.commons.gc.cuny.edu/engaging-womens-history-through-collaborativearchival-wikipedia-projects/.

Villeneuve, Cassidy. 2019. The Wikipedia assignment: praxis as pedagogy. Wiki Education. [Web page]. https://wikiedu.org/blog/2019/03/06/the-wikipedia-assignment-praxis-aspedagogy/.

Voyles, Elora C., Sarah F. Bailey \& Amanda M. Durik. 2015. New pieces of the jigsaw classroom: Increasing accountability to reduce social loafing in student group projects. The New School Psychology Bulletin 13(1). 11-20. http://www.nspb.net/index.php/nspb/article/view/264.

Wagner, Claudia, Eduardo Graells-Garrido, David Garcia \& Filippo Menczer. 2016. Women through the glass ceiling: Gender asymmetries in Wikipedia. EPJ Data Science 5(5). 1-24. https://epjdatascience.springeropen.com/articles/10.1140/epjds/s13688-016-0066-4. 